\title{
Aplikasi Musim Kearifan Masyarakat Gorontalo Berbasis Android
}

\author{
Salman Suleman ${ }^{1)}$, Roys Pakaya ${ }^{2)}$ \\ Program Studi Teknik Informatika, Politeknik Gorontalo \\ 60111,email :salmansuleman@poligon.ac.id, royspakaya@poligon.ac.id
}

\begin{abstract}
Di era sekarang, teknologi memegang peran penting dalam perkembangan potensi sumber daya manusia, terutama dalam bidang pertanian. Profesi petani juga membutuhkan kegiatan berbagi informasi dan berita terbaru mengenai media komunikasi yang praktis untuk digunakan. Oleh karena itu akhir-akhir ini mulai muncul aplikasi mengenai pertanian, dan kebanyakan berbasis web. Oleh karena itu tujuan dari peneliti ini adalah menghasilkan suatu aplikasi yang dapat membantu masyarakat dalam melakukan kebiasaan atau aktivitas seperti penentuan musim tanam, yang sesuai dengan cirri khas masyarakat Gorontalo, tidak lagi bertanya kepada orang yang lebih menguasai peran tersebut (Panggoba).

Penelitian ini ditujukan untuk menginventarisir kearifan lokal yang masih berlangsung untuk selanjutnya disusun dalam Aplikasi kalender musim praktek kearifan local masyarakat Gorontalo, dengan menerapkan metode penelitian sosial. Pada tahap berikutnya, luaran penelitian selanjutnya dianalisis dan dilakukan kajian peluang pengembangan aplikasi Komputerisasi, agar memudahkan masyarakat untuk memecahkan masalah yang akan di hadapai ketika menentukan musim tanam. Para petani dapat menggunakan teknologi ini sebagai tolak ukur pengetahuan tentang informasi bercocok tanam, sehingga dengan adanya informasi tersebut menjadi panduan atau pegangan bagi para petani, yang bertujuan sebagai cara meningkatkan hasil produktivitasnya.
\end{abstract}

Kata Kunci : aplikasi android, Panggoba, kalender musim kearifan masyarakat Gorontalo.

\section{PENDAHULUAN}

Perkembangan perangkat komunikasi telpon selular sekarang ini mengalami peningkatan yang sangat pesat yang didukung dengan disertakannya teknologi terbaru dengan perangkat semartphone android. Perkembangan itu juga tambah dengan konvernsi perangkat komunisa yang mampu menangani proses voice, data dan video dalam satu perangkat. Berbagai macam fitur pendukung juga di sertakan dalam perangkat ini, seperti pengolahan dokumen, gambar, video, konektivitas dan sebagainya.
Berdasarkan data ATSI (AsosiasiTeleponSeluler Indonesia) 20 Juni 2014 padatahun 2000 pelanggan telepon bergerak seluler Indonesia berjumlah sekitar 3,6 juta. Berdasarkan sumber yang sama, pada tahun 2012 angka tersebut meningkat seecara segnifikan menjadi sekitar 280 juta.

Begitu banyak perangkat mobile yang digunakan untuk mendukung kegiatan manusia, salah satunya adalah di bidangin formasi. Di era sekarang, teknologi memegang peran penting dalam perkembangan potensi sumber daya manusia, terutama dalam bidang pertanian. Profesi petani juga membutuhkan kegiatan berbagi informasi dan berita terbaru mengenai media komunikasi yang praktis untukdigunakan.

Oleh karena itu akhir-akhir ini mulai muncul aplikasi mengenai pertanian, dan kebanyakan berbasis web, maka dari itu, penyusun menyusulkan aplikasi berbasis mobile yang diharapkan dapat membantu meningkatkan kesejahteraan petani dan memangkas rantai distribusi hasil produksi daripetani. Selain itu banyak permasalahan petani yang dapat diselesaikan dengan penggunaan teknologi mobile seperti Aplikasi kalender musim tanam yang sesuai adat kebiasaan masyarakat Gorontalo.Yaitu Panggoba sebagai pedoman atau alat bantu, yang memberikan informasi special dan tabular tentang prediksi musim, untuk bercocok tanam di Provinsi Gorontalo.

Berdasarkan uraian dari permasalahan diatas penulis ingin mengajukan sebuah judul yakni“'Aplikasi Kalender Musim Kearifan Masyarakat Gorontalo Berbasis Android", adanya aplikasi ini di harapkan dapat membantu dan mempermudah petani Gorontalo dalam melihat atau memperkirakan musim tanam, berdasarkant radisi yang selama ini di lakukan secara turun temurun di Provinsi Gorontalo.

\section{METODE PENELITIAN}

\section{Gambaran UmumSistem}

Gambaran umum Aplikasi Kalender Kearifan Masyarakat Gorontalo Berbasis Android Gambar 1 berikut ini: 


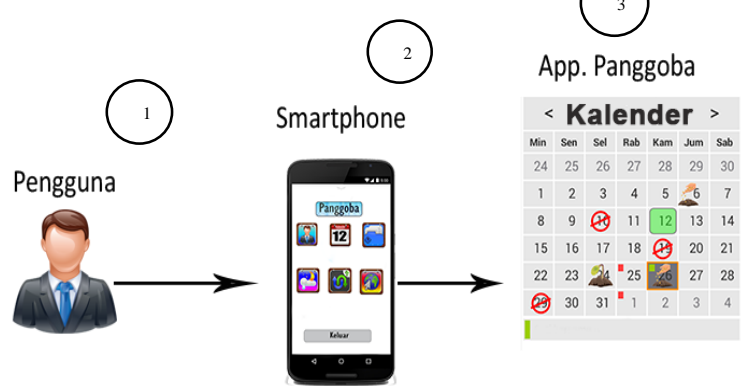

Gambar 1. Alur penggunaan Aplikasi Otoluwa

Deskripsi dari Gambar 1 adalah sebagai berikut ini :

1. Pengguna menggunakan smartphone android untuk memilih Menu Aplikasi yang diinginkan.

2. Smartphone android melakukan koneksi Aplikasi untuk mencari fitur menu yang akan di tujuh.

3. Informasi data Kalender yang diolah pada aplikasi yang akanditampilkan pada smartphone android.

\section{PERANCANGAN SISTEM}

\section{Use Case Diagram}

Use case diagram menggambarkan fungsionalitas yang diharapkan dari aplikasi Otoluwa, kebutuhan sistem darisudut pandang pengguna serta hubungan antara actor dan use case. Use case diagram aplikasi Otoluwa ditunjukkan

olehGambar 3

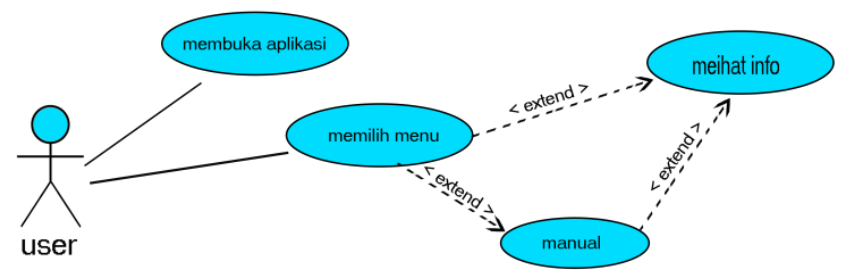

Gambar 3. Use Case Diagram

\section{Aktivity Diagram}

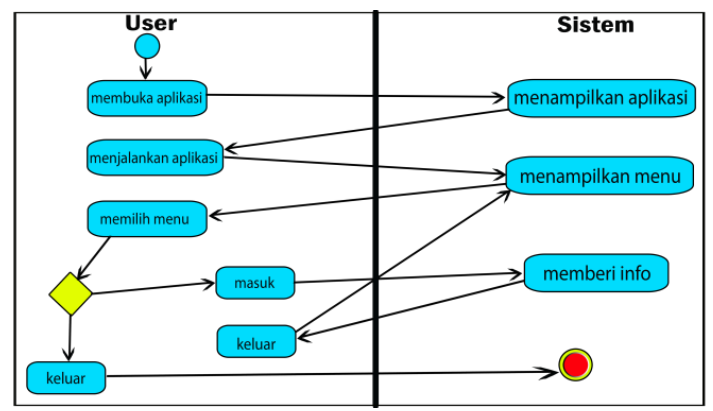

Gambar 2. Aktivity Diagram.

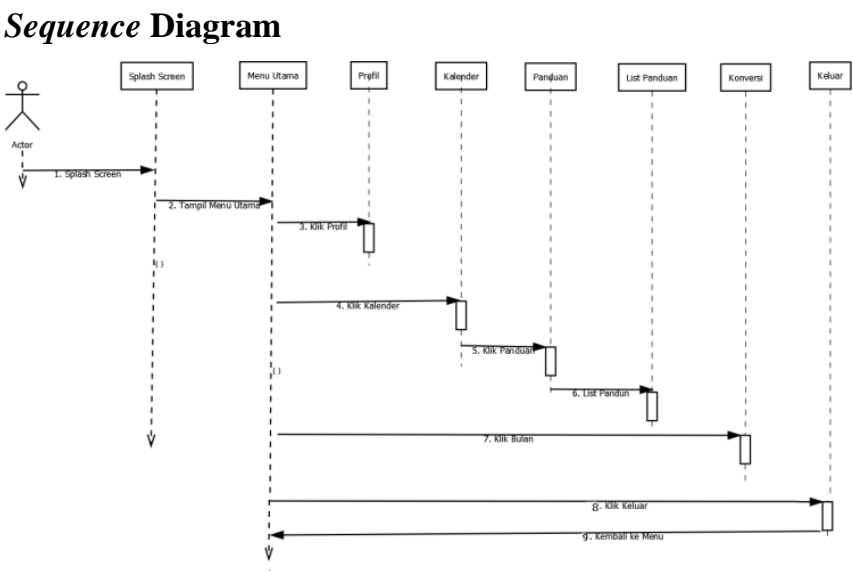

Gambar 4. Sequence Diagram

Deskripsi Sequence Diagram Aplikasi Otoluwa:

Squence Diagram diatas pertama-tama pengguna membuka aplikasi tampil

Tampilan splash screen kemudian masuk kehalaman menu utama, pilih kalender akan tampil list jadwal kalender dan masuk dalam tampilan kalender.

\section{DESAIN APLIKASI}

\section{RancanganTampilan (Interface)}

Aplikasi Otoluwa adalah sebuah aplikasi mobile yang memanfaatkan menu yang terdapat di dalam Smartphone untuk melakukan pemanggilan program. Hasil pemanggilan akan di tampilkan dalam bentuk gambar dan text. Aplikasi agar pengguna dapat merasakan kenyamanan, dan kemudahan dalam menggunakan aplikasi ini.

Untuk memudahkan para penggun amenggunakan aplikas iini. Berikut adalah rancangan tampilan mok up aplikasiOtoluwa.

\section{A. Rancangan Tampilan (Interface)}

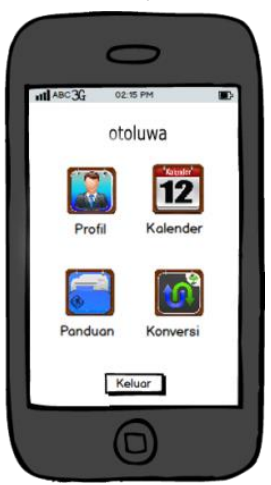

Gambar 5. Rancangan Login Sistem. 
Gambar 5 ini menggambarkan tampilan Dashboard Menu Utama pada bagian utama dari aplikasi ini yang menampilkanbeberapa menu dalam aplikasi otoluwa.

B. Rancangan tampilan Profil

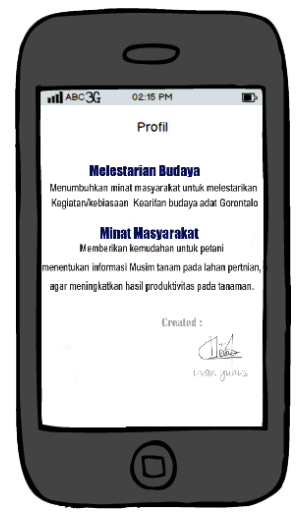

Gambar 6. Rancangan Tampilan Profil.

Kemudian pada tampilan menu profil yaitu penjelasan singkat tentang Aplikasi otoluwa.

\section{Rancangan Tampilan Kalender}

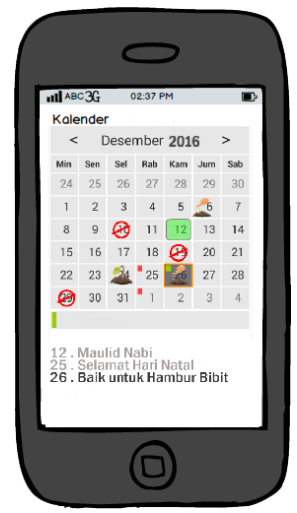

Gambar 7. Rancangan Menu Kalender.

Gambar 7 ini Kalender aplikasi akan menampilkan titik tanggal yang baik untuk bercocok tanam, dan hari-hari libur lainya. Selebihnya ada tambahan seperti tanggal ramalan (tanggal beserta ramalannya tetap sama, ditahun tahun yang akan datang cuman harinya mungkin yang akan berbeda).

\section{Rancntan tampilan Menu Panduan}

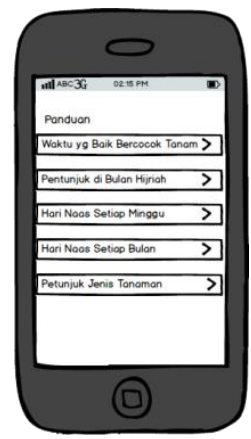

Gambar 8. RancangantampilanMenu Panduan.

Gambar 8 ini merupakan tampilan halaman untuk Yaitu menampilkan list untuk panduan dalam menentukan Hari naas pada setiap minggu, misalnya.

\section{E. Rancangan Tampilan Konversi}

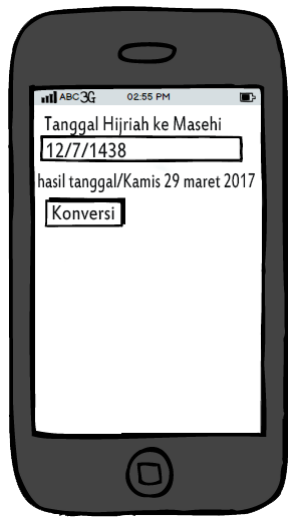

Gambar 9. Rancangan tampilan Konversi.

Gambar 9 ini merupakan tampilan halamanu ntuk menginputkan tanggal dari Hijriah ke Masehi.

\section{IMPLEMENTASI}

Setelah sistem dianalisis dan didesain secara rinci. Selanjutnya menuju tahap pengimplementasian. Pada tahap ini dapat dilihat bagaimana sistem yang dibuat beroperasi. Tahap ini bertujuan untuk mengevaluasi rancangan aplikasi, sehingga dapat memberikan masukan kepada perancang aplikasi.

\section{Tampilan Splashscreen}

Saat membuka aplikasi, akan muncul Splashscreen sekitar 5 detik. Kemudian Pengguna akan masuk kehalaman menu seperti yang ditampilkan pada Gambar 10.

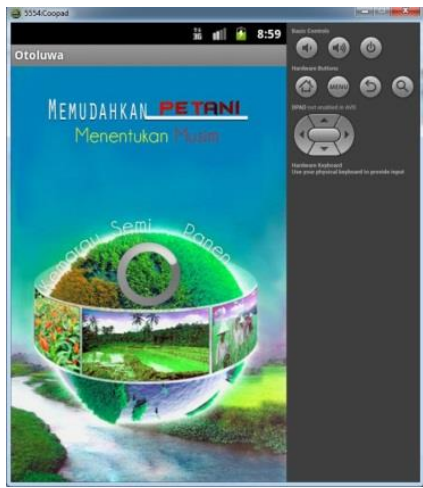

Gambar10. Spalshscreen 
Selanjutnya pada Halaman Utama terdapat 4 (empat) buah menu, yaitu menu daftar profil, Kalender, Buku, dan Konvreter .Pada menu Profil terdapat deskripsi tentang aplikasi Otoluwa, Menu Kalender untuk menampilkan sebuah kalender, Buku yaitu berisi list catatan tentang Otoluwa, Konversi yaitu untuk menkonversi Kalender Hijriah keMasehi

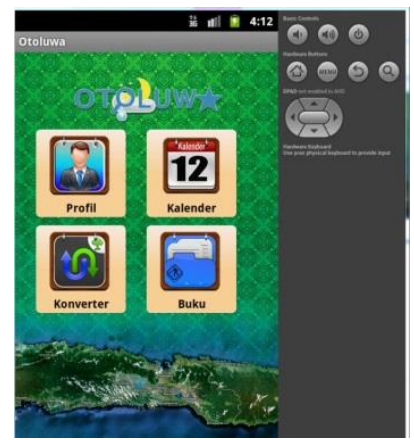

Gambar 11. Menu Aplikasi Otoluwa

Pada menu Profil Berisi deskripsi tentang manfaat aplikasi, seperti yang di tampilkan pada Gambar 11 .

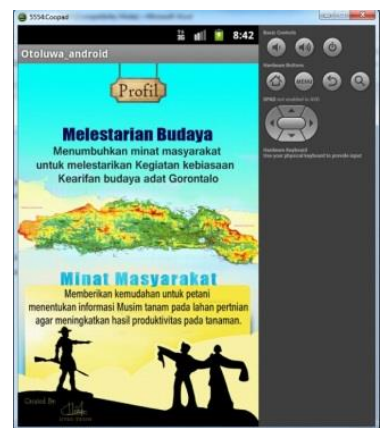

Gambar 12. Menu Profil

Halaman jadwal kalender Hulondalo menampilkan data jadwal hari Naas atau lowanga yang terjadi di setiap tanggal.Tampilan halaman kalender kegiatan dapat dilihat pada Gambar13.

\section{Menu Kalender}

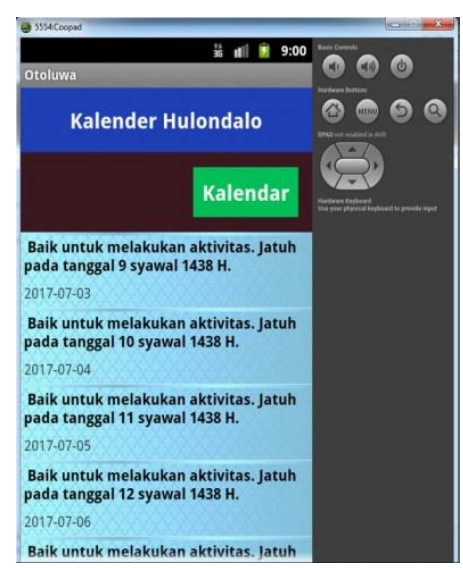

Gambar13. ListKalender

Dan ketika mengklik tombol kalender maka akan di ridarectke kalender utama seperti pada Gambar14.

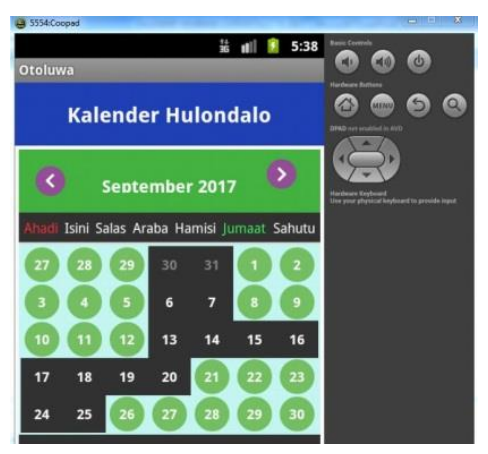

Gambar14. Kalender Hulondalo

Dan ketikameng klik tanggal yang menujukanhari Naas maka akan muncul alert dengan keteragan dari tanggal tersebut seperti yang terlihat pad agambar 15 .

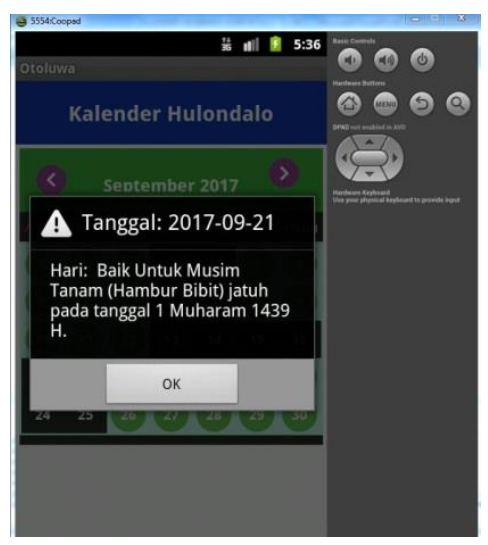

Gambar15. Tampilan Hari Naas

\section{Tampilan Konversi}

Kemudian pada menu selanjutnya yaitu menu konverter, pengguna bisa melakukan konversi tanggal, bulan, dan tahun hijriah ke masehi, mengingat data ramalan Gorontalo atau otoluwa menggunakan format atau tanggal hijriah.

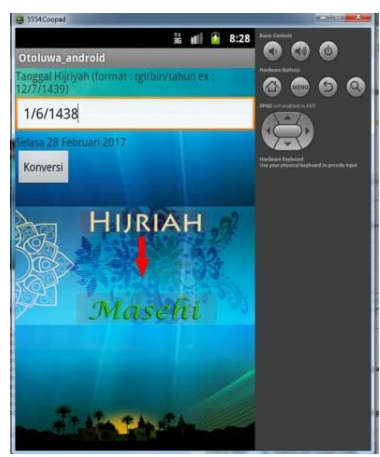

Gambar16. Konversi Hijriah KeMasehi 


\section{Tampilan List Buku}

Dan terakhir tampilan daftar panduan ramalan yang merupakan informasi pengetahuan tentang panggoba atau ramalan Gorontalo seperti yang terlihat pada Gambar 17.

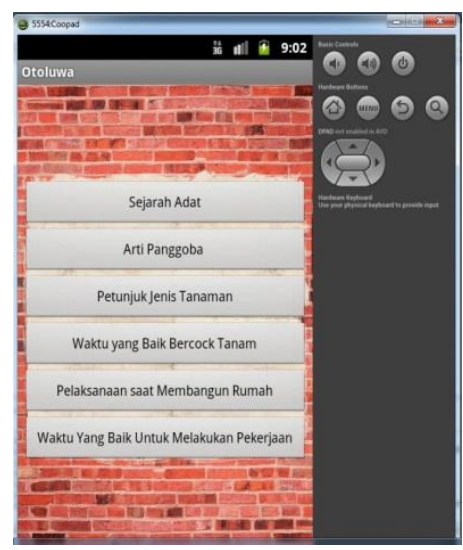

Gambar 17. List Buku

PadaGambar 17. Merupakan salah satu tampilan dari daftar panduan yang sudah dipilih yakni tampilan dari pelaksanaan panggoba.

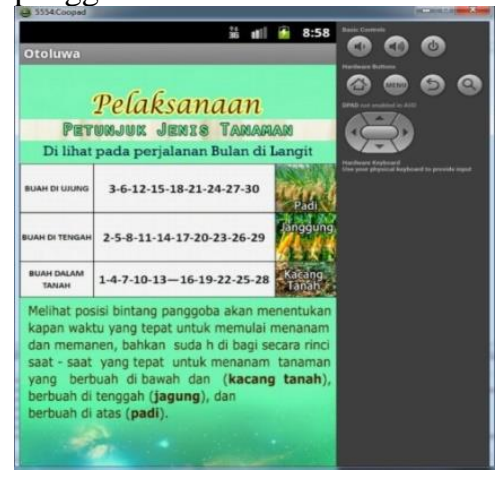

Gambar18. Dalam List Buku

\section{Tampilan Kelar}

Tampilan Exit merupakan tampilan untuk menampilkan dialog konfirmasi untuk keluar aplikasi. Untukkeluar (exit) dari aplikasi, user tinggal menekan tombol on Backpressed pada tampilan Home. Tampilan Exit dapat dilihat pada Gambar19.

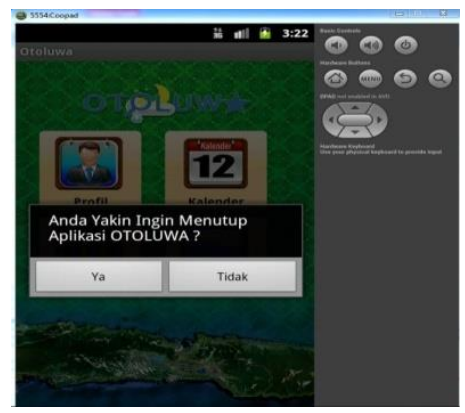

Gambar19. Keluardari Aplikasi Otoluwa

\section{KESIMPULAN}

1. Aplikasi ini dapat dijadikan masyarakat sebagai tolak ukur pengetahuan tentang informasi bercocok tanam, sehingga dengan adanya informasi tersebut menjadi panduan atau pegangan bagi para petani, yang bertujuan sebagai cara meningkatkan hasi produktivitasnya.

2. Untuk dapat menjalankan aplikasi ini, sebuah telepon genggam maupun tablet harus berplatform android tanpa mengunakan internet.

\section{SARAN}

Berikut ini saran yang dapat diberikan untuk pengembangan aplikasi ini lebih lanjut agar aplikasi ini menjadi lebih baik :

1. Penambahan fitur pada aplikasi disarankan, seperti Perkiraan Cuaca berdasarkan Areah Geografis lebih detil.

2. Peta yang ada dalam aplikasi masih menggunakan gambar, bisah di update menggunakan Google maps 3D.

3. Kapasitas memory pada Aplikasi ini diusahakan diperkecil lagi.

\section{DAFTAR PUSTAKA}

Dako, A. Y., \& Tamu, Y. (2016). Rancang Bangun Prototipe Sistem Informasi Kalender Musim Berbasis Kearifan Llokal Masyarakat Gorontalo, 365-372.

Kasmat Aransyah (2014) Proyeksi Jumlah Pelanggan Telepon Bergerak Seluler di Indonesia. Buletin Pos dan Telekomunikasi, Vol.12 No. 2 Junia 2014 :151166

Putik Sukmawati. (2013). Aplikasi Ramalan Primbon Jawa Berbasis Android Dengan Metode Pencarian Biner. Aplikasi Ramalan Primbon Jawa Berbasis Android Dengan Metode Pencarian Biner, 1-15.

Studi, P., Komputer, I., \& Mulawarman, F. U. (2011). Memahami Penggunaan UML ( Unified Modelling Language ), 6(1), 1-15.

Yunita A haliku. (2014). Otoluwa dan Perannya Dalam Masyarakat Gorontalo, 1-17. 